\title{
Effect of storage temperature on volatile marker compounds in cured loins fermented with Staphylococcus carnosus by brine injection
}

\author{
Ramona Bosse $^{1}$ (D) Melanie Wirth ${ }^{2} \cdot$ Jochen Weiss $^{2} \cdot$ Monika Gibis $^{2}$
}

Received: 12 May 2020 / Revised: 25 September 2020 / Accepted: 27 September 2020 / Published online: 20 October 2020

(c) The Author(s) 2020

\begin{abstract}
In this study, the influence of low $\left(5^{\circ} \mathrm{C}\right)$, intermediate $\left(15^{\circ} \mathrm{C}\right)$ and high $\left(25^{\circ} \mathrm{C}\right)$ storage temperatures on the profile of volatile compounds of North European cured loins fermented with Staphylococcus carnosus strains was investigated. In this context, proteolytic activity, bacterial growth, key volatile compounds and sensory attributes were studied. In conclusion, storage temperature significantly affected the volatile marker compounds. A multiple regression indicated significant effects of seven volatile compounds (acetophenone, benzaldehyde, butanone, 3-methylbutanal, 1-octen-3-ol, nonanal and pentanone) on the overall odor $\left(R^{2}=95.9 \%\right)$ and overall flavor $\left(R^{2}=81.1 \%\right)$. The sum of the marker volatiles aldehydes, ketones and alcohol increased with rising temperatures and the highest amounts of the odor active 3-methylbutanal up to $155 \mathrm{and} 166 \mathrm{ng} / \mathrm{g}$ meat were detected in high temperature-stored loins. Moreover, the addition of S. carnosus strain LTH 3838 showed maximum effect at $5{ }^{\circ} \mathrm{C}$-storage temperature in comparison to the control.
\end{abstract}

Keywords North European cured loin · Meat starter cultures · HS-trap GC · Meat processing · 3-Methylbutanal · Maturation

\section{Introduction}

Dry-cured meat products, such as raw hams or fermented sausages, are a popular and valuable group of meat products due to their typical texture and flavor $[1,2]$. The curing process of hams and loins prevents the meat from growth of spoilage and pathogenic microorganisms through the application of different hurdles, such as reduced water activity, increased salt content (partly with addition of nitrate and/ or nitrite) and low temperatures during curing [3]. Raw material quality, processing parameters, curing ingredients, microbiota as well as

Electronic supplementary material The online version of this article (https://doi.org/10.1007/s00217-020-03621-w) contains supplementary material, which is available to authorized users.

Monika Gibis

monika.gibis@uni-hohenheim.de

1 Division of Food Management and Technology, SRH Fernhochschule-The Mobile University, 88499 Riedlingen, Germany

2 Department of Food Physics and Meat Science, Institute of Food Science and Biotechnology, University of Hohenheim, 70593 Stuttgart, Germany other intrinsic and extrinsic factors influence the quality of cured ham or loin. Time and temperature profiles during ripening and storage particularly affect the profile of volatile compounds of cured hams and loins due to proteolytic, lipolytic and peptidolytic degradation processes in the cured meat matrix [4-8]. Traditional slowly matured dry-cured hams are mainly ripened at $15-18{ }^{\circ} \mathrm{C}$, and temperatures around $24{ }^{\circ} \mathrm{C}$ are used for quickly ripened hams [1]. However, the production temperatures $\left(5-15^{\circ} \mathrm{C}\right)$ are low for North European cured hams and loins $[9,10]$. In general, the processing, ripening and storage temperatures affect chemical reactions and enzymatic activities from intrinsic enzymes of the meat or added starter cultures, such as coagulase-negative staphylococci or micrococci. The demand for cured hams has increased and, therefore, accelerated processing conditions using not only higher ripening temperatures, but also starter cultures have become attractive to prevent spoilage and the growth of pathogenic bacteria and to control quality. Moreover, the application of starter cultures, such as Staphylococcus carnosus or S. xylosus strains, showed positive effects on the volatile profile (branched-chain amino acid catabolism, proteolytic and lipolytic activity) and the cured red color (nitrate reductase activity) as 
investigated in fermented sausages [11-13]. The volatile profiles of slowly matured dry-cured hams or fermented sausages from Spain, Italy or France have been studied extensively [14-16]. However, there is a lack of knowledge on the application and effects of starter cultures on North European cured hams and loins. Only research about surface starter cultures for example with Debaryomyces hansenii and Penicillium chrysogenum $[17,18]$ or with Lactobacillus spp. exists for cured pork loins [19]. The effect of an accelerated ripening and the addition of starter cultures can be investigated using sensory analysis as well as qualification and quantification of volatile compounds by chromatographic methods. A key step in the analysis of volatile compounds in cured loins is their isolation and enrichment prior to analysis, so a combination of a static headspace (HS) technique with an adsorption trap was used in the present study.

The aim of this study was to investigate the influence of low $\left(5^{\circ} \mathrm{C}\right)$, intermediate $\left(15^{\circ} \mathrm{C}\right)$ and high $\left(25^{\circ} \mathrm{C}\right)$ storage temperatures (post-ripening) on key volatiles of North European cured loins as a model muscle for other cured hams fermented with S. carnosus strain LTH 3838 during a ripening time of 12 weeks. We hypothesized that key volatile compounds and proteolytic activity increased as well as sensory quality by the addition of a proteolytic starter culture in combination with higher storage temperatures after manufacturing steps. Therefore, the key volatile compounds, proteolytic activity and sensory attributes were investigated. This study was conducted as a first step toward an industrial use of starter cultures to find the most suitable ripening and storage process for North European cured hams and loins inoculated with $S$. carnosus cultures by brine injection.

Table 1 Overview of the production and end product parameters (mean \pm standard deviation; total: mean value over all batches) of all cured loin batches cured either without a starter culture (control) or

\section{Materials and methods}

\section{Selection and preparation of starter cultures}

Staphylococcus carnosus strain LTH 3838 was characterized as a potential starter in a former study [20]. This strain was isolated from fermented fish and was demonstrated to digest sarcoplasmatic proteins [20]. For the production of a bacterial suspension with approximately $1 \times 10^{11} \mathrm{cfu} / \mathrm{mL}$, the strain was routinely grown in $100 \mathrm{~mL}$ standard 1 nutrient broth (Merck, Darmstadt, Germany) in $300 \mathrm{~mL}$ Erlenmeyer flasks at $37^{\circ} \mathrm{C}$ for $24 \mathrm{~h}$ with shaking at $180 \mathrm{rpm}$ (Innova 42, Eppendorf, Hamburg, Germany). Cells were concentrated by centrifugation of the overnight culture $(2500 \times \mathrm{g}, 10 \mathrm{~min}$, $4{ }^{\circ} \mathrm{C}$; Hermle Z $32 \mathrm{HK}$, Wehingen, Germany) and washed twice with $0.9 \%$ (w/v) sodium chloride solution ( $\mathrm{NaCl}$ solution; Carl Roth, Karlsruhe, Germany). Finally, the cells were resuspended in $1 \mathrm{~mL} \mathrm{NaCl}$ solution.

\section{Manufacture of cured loins}

Fresh pork loins (M. longissimus dorsi; $\mathrm{pH} 5.41 \pm 0.08$; Table 1) were obtained from a local retailer (MEGA, Stuttgart, Germany) and manufacturing was carried out as described with some modifications (Fig. 1) [21]. The pork loins were injected with brine inoculated with $S$. carnosus LTH 3838 to introduce the starter cultures into the center of the loin. Nevertheless, the main salting was carried out by dry-curing. The influence of temperature was investigated during 12 weeks of storage at temperatures of $5{ }^{\circ} \mathrm{C}$ [cold storage (low)], $15^{\circ} \mathrm{C}$ [standard storage temperature (intermediate)] and $25{ }^{\circ} \mathrm{C}$ [ambient temperature (high)] for cured loins with (starter-S) and without $S$. carnosus strain (control-C). For all cured loin batches, the brine (30

with $S$. carnosus LTH 3838 (starter): $\mathrm{pH}$ of raw meat $(\mathrm{n}=18$, except for $15{ }^{\circ} \mathrm{C}$ control and starter: $\left.\mathrm{n}=6\right)$, and injection weight of brine $(\%$, $\mathrm{n}=6$, except for $15^{\circ} \mathrm{C}$ control and starter: $\mathrm{n}=3$ )

\begin{tabular}{|c|c|c|c|c|c|c|c|}
\hline \multirow[t]{2}{*}{ Batch } & \multirow{2}{*}{$\begin{array}{l}\text { Tempera- } \\
\text { ture }\left({ }^{\circ} \mathrm{C}\right)\end{array}$} & \multicolumn{2}{|c|}{ Raw product (week 0) } & \multicolumn{4}{|c|}{ Product at end of storage (week 15) } \\
\hline & & $\mathrm{pH}$ raw meat & Injection weight (\%) & $\mathrm{pH}$ cured loin & Weight loss (\%) & Moisture content (\%) & $a_{\mathrm{w}}$ value \\
\hline Control & 5 & $5.31 \pm 0.04^{\mathrm{a}}$ & $9.79 \pm 1.79^{\mathrm{a}}$ & $5.59 \pm 0.07^{\mathrm{ab} *}$ & $22.34 \pm 1.91^{\mathrm{a}}$ & $63.6 \pm 1.3^{\mathrm{a}}$ & $0.913 \pm 0.006^{\mathrm{a}}$ \\
\hline Starter & 5 & $5.38 \pm 0.03^{\mathrm{bc}}$ & $10.32 \pm 1.72^{\mathrm{a}}$ & $5.64 \pm 0.04^{\mathrm{a} *}$ & $20.88 \pm 1.37^{\mathrm{a}}$ & $61.1 \pm 3.3^{\mathrm{ab}}$ & $0.915 \pm 0.006^{\mathrm{a}}$ \\
\hline Control & 15 & $5.42 \pm 0.05^{\mathrm{be}}$ & $8.50 \pm 0.55^{\mathrm{a}}$ & $5.52 \pm 0.07^{\mathrm{bc} *}$ & $22.68 \pm 1.20^{\mathrm{a}}$ & $61.5 \pm 0.9^{\mathrm{ab}}$ & $0.911 \pm 0.006^{\mathrm{a}}$ \\
\hline Starter & 15 & $5.37 \pm 0.03^{\mathrm{c}}$ & $8.35 \pm 1.65^{\mathrm{a}}$ & $5.47 \pm 0.06^{\mathrm{c} *}$ & $22.68 \pm 1.39^{\mathrm{a}}$ & $61.3 \pm 2.5^{\mathrm{ab}}$ & $0.913 \pm 0.004^{2}$ \\
\hline Control & 25 & $5.51 \pm 0.06^{\mathrm{d}}$ & $9.23 \pm 1.44^{\mathrm{a}}$ & $5.99 \pm 0.25^{\mathrm{d} *}$ & $22.47 \pm 1.36^{\mathrm{a}}$ & $61.0 \pm 2.4^{\mathrm{ab}}$ & $0.907 \pm 0.003^{\mathrm{a}}$ \\
\hline Starter & 25 & $5.44 \pm 0.04^{e}$ & $9.44 \pm 1.29^{\mathrm{a}}$ & $5.94 \pm 0.07^{\mathrm{d} *}$ & $21.35 \pm 0.77^{\mathrm{a}}$ & $60.3 \pm 2.2^{\mathrm{b}}$ & $0.915 \pm 0.006^{\mathrm{a}}$ \\
\hline Total & & $5.41 \pm 0.08$ & $9.44 \pm 1.52$ & - & $21.94 \pm 1.45$ & $61.0 \pm 2.5$ & $0.912 \pm 0.007$ \\
\hline
\end{tabular}

End product parameters were investigated after 12 weeks of storage at three different temperatures: $5{ }^{\circ} \mathrm{C}, 15^{\circ} \mathrm{C}$ and $25^{\circ} \mathrm{C}$ (week 15 ): weight loss during drying $\left(\%, n=6\right.$, except for $15^{\circ} \mathrm{C}$ control and starter: $n=3$; measured till week 3; Supplemental material 2), pH of the cured loins $(n=6)$, moisture content $\left(\%, n=18\right.$, except for batch $15{ }^{\circ} \mathrm{C}$ control and starter: $\left.n=9\right)$ and water activity $\left(a_{\mathrm{w}}\right.$ value, $\left.n=6\right)$. Different letters indicate significant differences between batches within 1 week and $*$ indicate significant differences of pH over time (confidence level $\alpha=0.05$ ) 
L) contained $10 \%(\mathrm{w} / \mathrm{w})$ nitrite curing salt (Südsalz, Heilbronn, Germany; $0.9 \% \mathrm{NaNO}_{2}$ ). The brine of the starter batches was inoculated with $1 \mathrm{~mL}$ of a bacterial suspension, which contained approximately $1 \times 10^{11} \mathrm{cfu} / \mathrm{mL}$ containing $1 \times 10^{7}-10^{8} \mathrm{cfu} / \mathrm{mL}$ in the brine. All pork loins were injected with the brine using a multi-needle injector (105 MC2 R, Günther, Dieburg, Germany) with the following settings: 105 needles ( $2 \mathrm{~mm}$ diameter, $2 \times 0.8 \mathrm{~mm}$ hole size), 0.7 bar injection pressure, triple injection in two-way mode with $50 \%$ needle bar speed to reach an injection weight of approximately $10 \%(\mathrm{w} / \mathrm{w}$; percentage of weight difference before and after injection) (Supplemental material 1). Directly after injection, a dry-curing step was conducted to reach a total amount of curing salt of $40 \mathrm{~g}$ curing salt per 1 $\mathrm{kg}$ fresh meat. The loins were cured for 7 days at $5^{\circ} \mathrm{C}$. An Air Master UK-1800 BE climatic chamber (Reich, Urbach, Germany) was used for drying and mild smoking (at $24^{\circ} \mathrm{C}$ ) for an additional 7 days at temperatures of $10-15^{\circ} \mathrm{C}$ with a relative humidity gradient from 85 to $75 \%$ relative humidity (Supplemental material 3). For the adjustment of a uniform final weight loss of approximately $22 \%(\mathrm{w} / \mathrm{w}$; based on raw meat weight), the loins were stored at $15{ }^{\circ} \mathrm{C}$ at $75 \%$ relative humidity, weighed daily and were then vacuum packed (week 3) (Supplemental material 2). During storage, the influence of temperature on the final vacuum-packed loins was studied after 12 weeks at three different temperatures. The cold storage of vacuum-packed cured loins, which is typical in the food industry, was conducted at $5{ }^{\circ} \mathrm{C}$. A storage at $15^{\circ} \mathrm{C}$ is the standard process in cured ham and loin production and $25^{\circ} \mathrm{C}$ is a typical short ripening high temperature process for dry-cured hams [1]. Sampling was carried out in week 0 (raw material, cured loins after injection and brine), week 3 (end product at $22 \%$ weight loss; start of storage) and after 12 weeks of ripening (week 15; end of storage). All cured loins and analyses were carried out in duplicate.

\section{Measurement of pH and water activity}

The measurement of the $\mathrm{pH}$ (pH537, WTW, Weilheim i. OB, Germany), moisture content (oven drying method) [22] and water activity ( $a_{\mathrm{w}}$ value; AQUALAB CX-2, Decagon Devices, Inc., Pullman, United States of America) was carried out at the start of processing (week 0 ) and the end of the storage (week 15). All analyses were repeated three times for each loin in duplicate.

\section{Microbial analysis}

An approximately $10 \mathrm{~g}$ meat sample was weighed in a stomacher bag (VWR International, Darmstadt Germany), diluted 1:10 gravimetrically in peptone water (Carl Roth, Karlsruhe, Germany) and homogenized for
$90 \mathrm{~s}$ (Stomacher, IUL instruments, Barcelona, Spain) as described in a recent study [21]. Samples were serially diluted in peptone water and plated in duplicate on Plate Count agar (AppliChem, Darmstadt, Germany) for the detection of the total viable counts and on Baird Parker agar (Carl Roth, Karlsruhe, Germany), and then mixed with $10 \mathrm{~mL}$ of $1 \%$ potassium tellurite solution (Sigma Aldrich, Steinheim, Germany). Therefore, $100 \mu \mathrm{L}$ aliquots of 1:10 dilutions were spread-plated or $50 \mu \mathrm{L}$ aliquots of $10^{-2}-10^{-4}$ dilutions were spiral-plated using an automated spiral plater (Don Whitley Scientific Limited, West Yorkshire, UK). Plate Count agar was incubated for $48 \mathrm{~h}$ at $37^{\circ} \mathrm{C}$ and Baird Parker agar was incubated for $72 \mathrm{~h}$ at $37^{\circ} \mathrm{C}$. Colony forming units (cfu) were measured using a colony counting device (aCOLyte, Synbiosis, Cambridge, UK). Additional sampling was carried out in weeks 1, 2 and 9 to track microbial changes during processing and storage.

\section{Determination of key volatiles}

The analysis of volatile compounds was performed by using a method with a headspace-trap gas chromatography system (Perkin Elmer, Rodgau, Germany) [23]; TurboMatrix 40 Trap Headspace sampler directly coupled to a Clarus ${ }^{\circledR}$ GC 580 with a flame ionization detector (fused silica capillary column Rtx $^{\circledR}-200$ (30 m, 0.32 mm internal diameter, $1 \mu \mathrm{m}$ film thickness; Restek, Bellefonte, USA), $70 \mathrm{kPa}$ column pressure, helium as carrier gas); software: Turbo Matrix (version 2.5.0) and TotalChrom Workstation (version 6.3.2). The following marker volatile compounds were investigated: 2-butanone, 3-methylbutanal, 2-pentanone, acetoin, hexanal, 1-octen-3-ol, benzaldehyde, nonanone, nonanal and acetophenone. On the sampling day, core samples of each loin were taken. The samples were frozen by immersion in liquid nitrogen and immediately minced using a blender (Moulinette D56, Moulinex/Krups, Frankfurt am Main, Germany). They were vacuum packed and stored at $-20{ }^{\circ} \mathrm{C}$ until analysis. For analysis, $1.5011 \pm 0.0005 \mathrm{mg}$ of cured loin was weighed directly into headspace vials $(22 \mathrm{~mL}$, Perkin Elmer, Rodgau, Germany), $1.49 \mathrm{~mL}$ saturated sodium chloride solution ( $\geq 99.9 \%$; Carl Roth, Karlsruhe, Germany) and $10 \mu \mathrm{L}$ internal standard solution $(1.07 \mathrm{mg} / \mathrm{mL}$ eugenol (99.6\%; Sigma-Aldrich, Steinheim, Germany) in ethanol (99.9\%; VWR, Darmstadt, Germany) were added. After capping (20 mm crimp top aluminum silver caps with PTFE/ silicone septa, Perkin Elmer, Rodgau, Germany), the vials were slightly mixed using a vortex. The settings for the HStrap and GC used and the validation of the method were described in a prior method [23]. All chemicals (at highest purities) were purchased from Sigma-Aldrich (Steinheim, Germany). Three replicates per sample were measured. 


\section{Proteolytic activity}

A modified Lowry assay [24] was used to determine the tyrosine value as a parameter for proteolytic activity in the cured loins produced. Samples were cut out of the core of the cured loin slices at weeks $0,3,9$ and 15 and stored vacuum packed at $-20^{\circ} \mathrm{C}$ until analysis. The analysis procedure followed the reported method [25]. All measurements were performed from duplicate and measured three times.

\section{Sensory analysis}

The sensory test was carried out at the beginning (week 3 ) and the end of storage (week 15) in the sensory laboratory room. A panel of 20 assessors (all experts in the field of meat science with training about sensory attributes of cured ham and loin) rated the overall aromatic odor and the overall aromatic taste of the three inoculated cured loins stored at different temperatures, in comparison to the corresponding control batch (same temperature) as a reference standard under color masking light. Therefore, cured loin slices with a thickness of approximately $2 \mathrm{~mm}$ (Bizera VS8A, Balingen, Germany) were prepared and core samples with a diameter

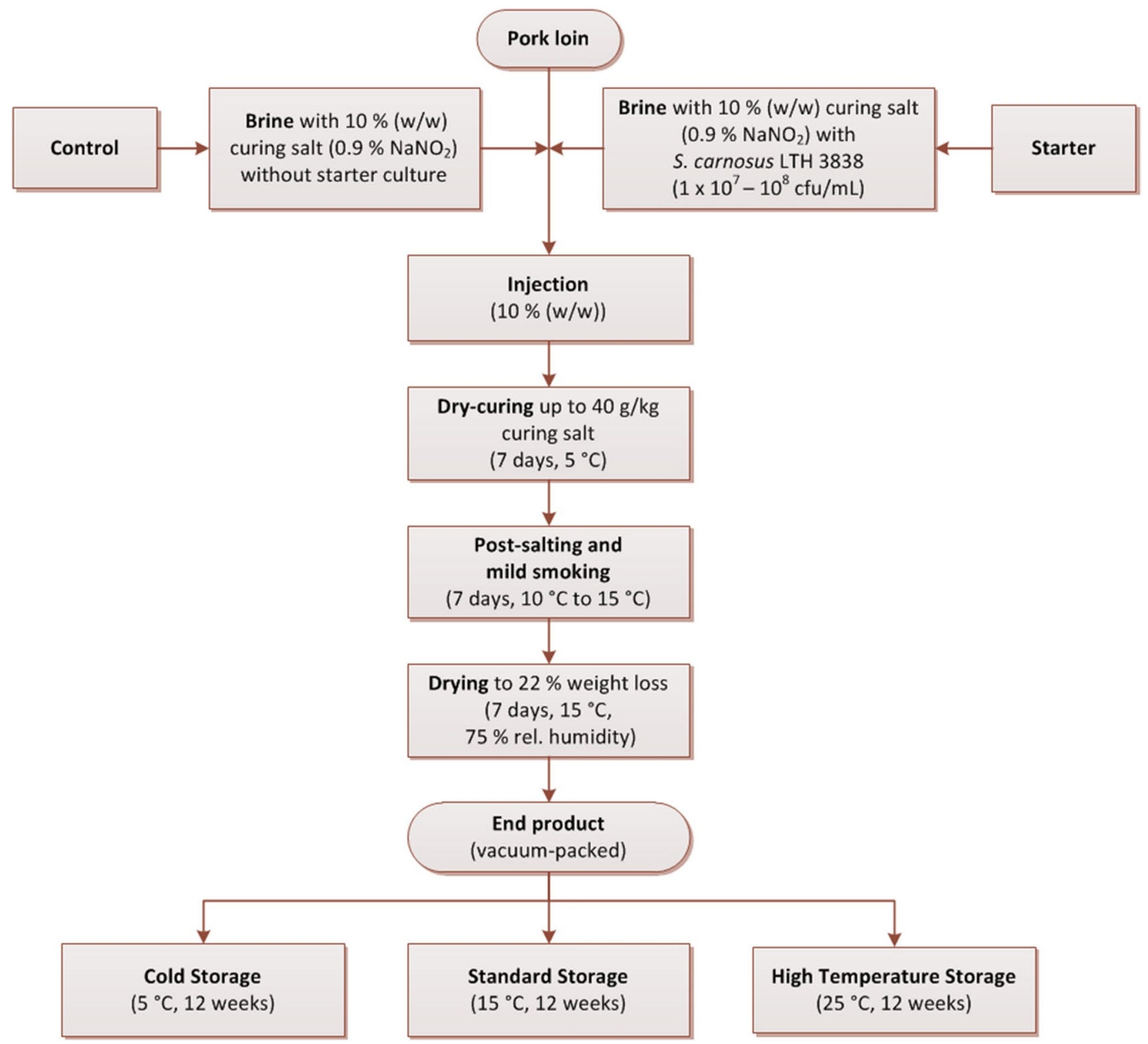

Fig. 1 Flow diagram of the cured loin production process 
of approximately $25 \mathrm{~mm}$ were punched out. The samples were presented to the assessors $(n=40)$ at ambient temperature. A scale from 0 (low intensity) to 6 (high intensity) was used. The reference standard was set to the middle of the scale (score 3). The test of the sensory panel was carried out in duplicate. Additionally, an olfactory analysis was carried out with a minimum of 15 assessors, selected and olfactory trained according to DIN 1096:1996-08 (Supplemental material 4). The following attributes were defined for the standards used for training with concentrations given in parentheses: grassy (hexanal: $0.08-0.83 \mu \mathrm{g} / \mathrm{mL}$ ), buttery (acetoin: $1.0-100.0 \mu \mathrm{g} / \mathrm{mL}$ ), almond-like (benzaldehyde: $0.10-10.44 \mu \mathrm{g} / \mathrm{mL}$ ), flowery-sweet (acetophenone: $0.21-20.60 \mu \mathrm{g} / \mathrm{mL}$ ) and cheesy-rancid (3-methylbutanal: $4.02-40.15 \mu \mathrm{g} / \mathrm{mL}$ ). For this, $10 \mathrm{~mL}$ of the standard solution or a mixture was presented to the olfactory assessors at ambient temperature in coverable glasses. The cured loins were sliced (thickness, $5 \mathrm{~mm}$ ) (Bizera VS8A, Balingen, Germany) and core samples with a diameter of approximately $16 \mathrm{~mm}$ were punched out and presented to the olfactory assessors at ambient temperature in coverable glasses.

\section{Statistical analysis}

Statistical analysis was conducted with Statgraphics ${ }^{\circledR}$ (Centurion XV, version 15.2.11, StatPoint Technologies, Inc.). The Shapiro-Wilks test, Levene's test and Grubbs' test were used to test statistical assumptions. Multiple-sample analysis (multiple ANOVA, multiple-range test with Fisher's least significant difference (LSD), Pearson correlation coefficient) or nonparametric tests were used (Kruskal-Wallis test, Mann-Whitney (-Wilcoxon) test, Spearman rank correlation coefficient), because most of the data did not meet the assumption of normality or homoscedasticity [26]. A confidence level of $\alpha=0.05$ was used for all statistical calculations. A multiple regression analysis in backward selection $(\alpha=0.1)$ was carried out using mean values of all volatile compounds and sensory scores of all inoculated cured loin samples to confirm volatile compounds with an influence on overall odor and overall taste.

\section{Results and discussion}

\section{Technological and microbial characterization}

The technological parameters such as $\mathrm{pH}$, temperature and moisture content as well as microbial parameters influence the development of flavor [1]. The $\mathrm{pH}$ value of the fresh pork loin was between 5.25 and 5.61 (Table 1, week 0). All $\mathrm{pH}$ values increased significantly during cured loin production from week 0 to 15 from mean $\mathrm{pH}$ values of 5.41-5.73 (Table 1). A study, which investigated Black Forest hams inoculated with Staphylococcus equorum and Tetragenococcus halophilus strains, observed $\mathrm{pH}$ values in a range of 5.6-5.75 [27]. Significantly higher $\mathrm{pH}$ values were observed for the loins stored at $25{ }^{\circ} \mathrm{C}$ in comparison to a storage at $5{ }^{\circ} \mathrm{C}$ and $15{ }^{\circ} \mathrm{C}$. Within the respective storage temperatures, no significant differences between control and starter batches were found. The production of cured loins included an injection process $(9.44 \pm 1.52 \%$, w/w) to introduce the S. carnosus strains in the center of the pork loins, where no significant differences in the injection weights were determined (Table 1). Prior to the transfer of the cured loins to the different storage temperatures, a homogenous mean weight loss of approximately $22 \%(\mathrm{w} / \mathrm{w})(21.94 \pm 1.45 \%$, $\mathrm{w} / \mathrm{w}$ ) was adjusted (Table 1 ). Consequently, the moisture content and the water activity showed no significant differences (Table 1). The mean $a_{\mathrm{w}}$ value of 0.912 is comparable to those of another study for German Black Forest hams [27] and for the inoculated pork loins after 28 days of aging [19]. The total viable and staphylococcal counts for the fresh pork loin were $3.7 \pm 0.2 \mathrm{log} \mathrm{cfu} / \mathrm{g}$ meat and $2.1 \pm 0.2 \mathrm{log} \mathrm{cfu} / \mathrm{g}$ meat, respectively. The injection brine of the control batch contained 3.4 $\pm 0.1 \log \mathrm{cfu} / \mathrm{mL}$ and less than $2.0 \log \mathrm{cfu} / \mathrm{mL}$ for total viable and staphylococcal count, respectively. On the other hand, the brine inoculated with $S$. carnosus LTH 3838 reached $6.9 \pm 0.1 \log \mathrm{cfu} / \mathrm{mL}$ and $6.0 \pm 0.2 \log \mathrm{cfu} / \mathrm{mL}$ for total viable and staphylococcal count, respectively. The total viable counts, as well as the staphylococcal counts for the control loins, decreased during the first 2 weeks, while the loins were cured and dried at lower temperatures (Fig. 2 and Supplementary material 2). With rising temperature, the bacterial growth started for the control loins (Fig. 2). These microbial developments were in line with the findings for Black Forest hams [27]. The storage at $25^{\circ} \mathrm{C}$ led to significantly higher total viable and staphylococcal counts for the control batch at the end of storage (Fig. 2). The positive effect of temperature on bacterial growth is well known $[28,29]$. The total viable and staphylococcal counts of the inoculated cured loins decreased over the process about 0.5-2 log cfu/g meat, respectively (Fig. 2). The decreasing tendency of the starter culture seems to indicate higher stress conditions for the inoculated cultures due to higher $\mathrm{pH}$ values, higher and homogenous salt content and low nutrient level [29], while the starter-inoculated loins stored at lower temperatures showed higher cell counts at the end of storage. Increased stress conditions showed that bacterial growth decreased with increasing salt concentration at high temperatures and high $\mathrm{pH}$ values [29].

\section{Proteolytic activity}

The proteolytic activity was measured as tyrosine level to observe the overall release of amino acids from proteins by proteolytic activity of meat intrinsic proteases such as 
(a)

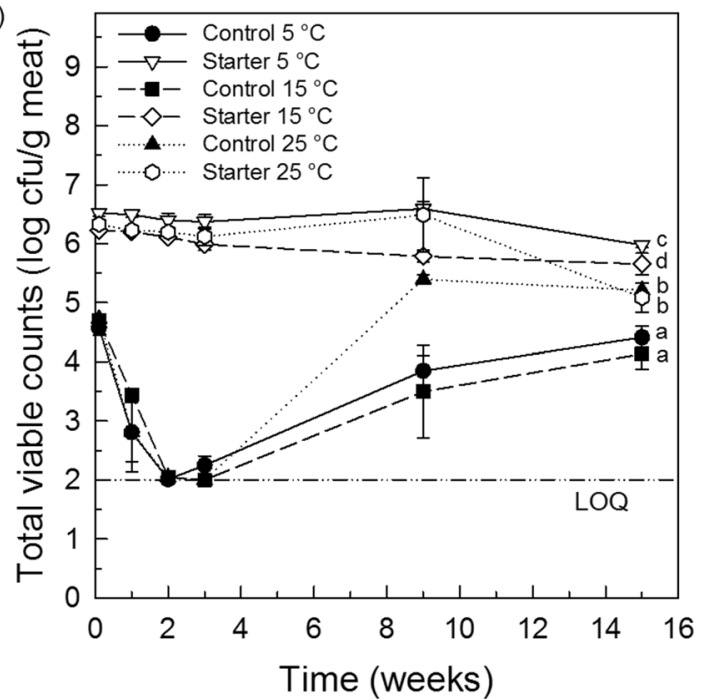

Fig. 2 Results of the microbiological studies (mean \pm standard deviation) of a the total viable counts (determined on Plate Count agar, $37{ }^{\circ} \mathrm{C}, 48 \mathrm{~h}$ ) and $\mathbf{b}$ the staphylococcal counts (Baird Parker agar, $37{ }^{\circ} \mathrm{C}, 72 \mathrm{~h}$ ) over time (weeks) in log cfu/g meat for all cured loin batches cured either without a starter culture (control) or with $S$. car-

cathepsins and exopeptidases, as well as bacterial enzymes, which can serve as volatile precursors [30, 31]. The tyrosine values of fresh pork loin varied between batches (Fig. 3). The tyrosine content significantly increased for all batches due to the proteolytic activity of intrinsic and microbial enzymes $[30,31]$. The tyrosine development is in line with the earlier described study [25], which investigated the tyrosine content in meat pieces treated with (1-2.3 mg tyrosine/g meat) or without a protease ( $0.8-1.2 \mathrm{mg}$ tyrosine/g meat). The tyrosine content significantly increased with rising temperatures due to the higher enzyme activity at higher temperatures (Fig. 3) [30, 31]. Moreover, the increasing proteolytic activity led to an increase of $\mathrm{pH}$ due to the release of peptides and amino acids (Table 1) [1]. At the end of storage, the tyrosine content of the inoculated cured loins stored at $5{ }^{\circ} \mathrm{C}$ was significantly higher than that of the control. This can be linked to the results of the microbial study, where a higher total viable count was observed for the batch inoculated with the proteolytic S. carnosus strain (Fig. 2). In addition, for the strains Staphylococcus xylosus SS4 and Staphylococcus carnosus SC54, the highest extracellular proteinase activity was detected as well as substrate-specific aminopeptidase activity with L-methionine, L-leucine and L-phenylalanine as N-terminal residue [32]. These released peptides and amino acids are known to be involved in flavor formation and could contribute to odor and taste impression of cured meat products $[32,33]$. An increase in the storage temperature to $15^{\circ} \mathrm{C}$ or $25^{\circ} \mathrm{C}$ led to comparable tyrosine and $\mathrm{pH}$ values between the starter and control batches (within the storage temperature). (b)

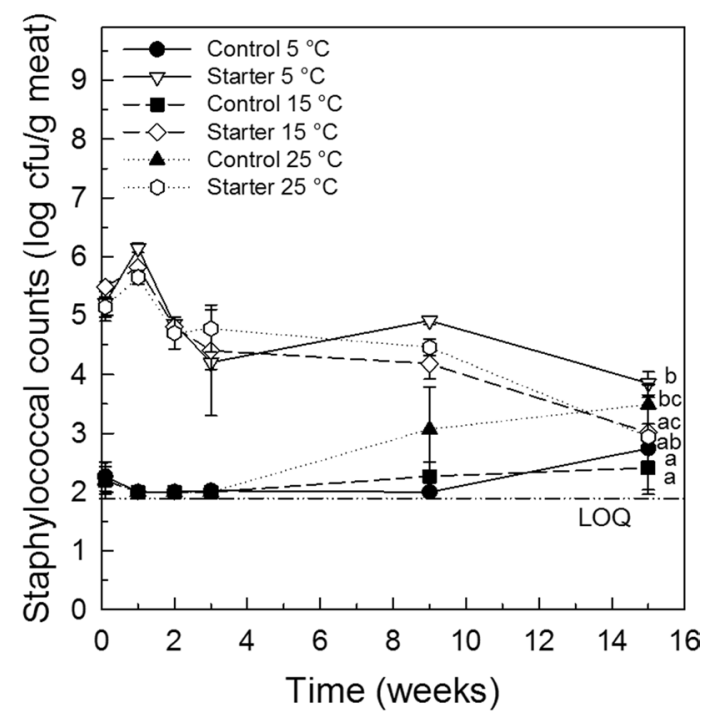

nosus LTH 3838 (starter) ( $n=8$, LOQ-limit of quantification of 2 $\log \mathrm{cfu} / \mathrm{g}$ meat as dash-dot-dot line) and stored either at $5{ }^{\circ} \mathrm{C}, 15^{\circ} \mathrm{C}$ and $25{ }^{\circ} \mathrm{C}$. Different letters indicate significant differences between batches at the end of storage (week 15) (confidence level $\alpha=0.05$ )

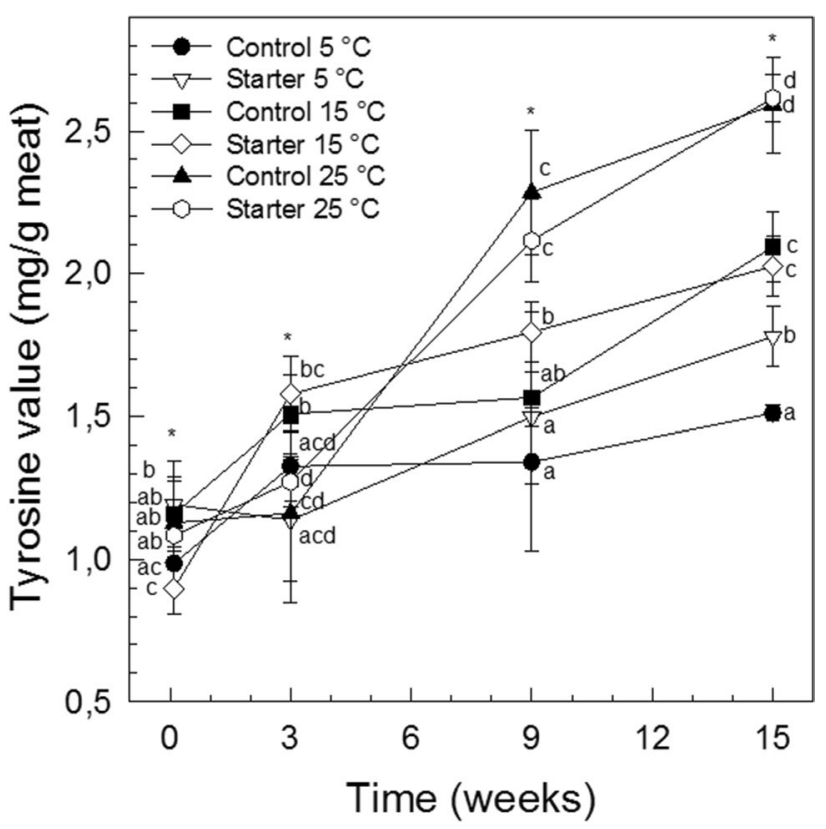

Fig. 3 Proteolytic activity (mean \pm standard deviation) of all cured loin batches cured either without starter culture (control) or with $S$. carnosus LTH 3838 (starter) at different storage temperatures of $5{ }^{\circ} \mathrm{C}$, $15^{\circ} \mathrm{C}$ and $25^{\circ} \mathrm{C}$ over time (weeks) measured as tyrosine value $(\mathrm{mg} / \mathrm{g}$ meat) $(n=12)$. Different letters indicate significant differences over time within one batch and $*$ indicates significant differences between batches within 1 week (confidence level $\alpha=0.05$ ) 
Moreover, the multiple ANOVA showed significant effects for temperature $(p<0.01)$ and time $(p<0.01)$, but no significant effects for the usage of the starter culture. These results are in line with studies that showed that major proteolytic activity is provided by intrinsic proteases, but that microbial proteinases and aminopeptidases can lead to the release of peptides and amino acids as precursors for volatiles during ripening and storage $[30,32,34,35]$.

\section{Sensory analysis}

At the beginning of storage (week 3), the overall odor showed no significant differences between the batches as analyzed by the sensory panel. Starter-injected loins stored at $15{ }^{\circ} \mathrm{C}$ showed significantly less overall taste in comparison to the control (Table 2). At the end of storage (week 15), the starter-injected loins stored at $15{ }^{\circ} \mathrm{C}$ and $25^{\circ} \mathrm{C}$ (significant) showed the highest values, 3.3 and 3.4, respectively (Table 2). The overall taste of the starter-inoculated loins increased for the storage temperatures of $15{ }^{\circ} \mathrm{C}$ and $25^{\circ} \mathrm{C}$ to 3.4 and 3.3, respectively. The scores for the overall odor and taste increased for the loins with starters by using rising temperatures. These results are in accordance with the study about Black Forrest hams, which demonstrated a higher sensory acceptance of inoculated cured hams (with S. equorum and T. halophilus strains) in comparison to control hams without starter cultures [27]. The olfactory-trained panel investigated the grassy, buttery, almond-like, flowery/sweet and cheesy/rancid odor of the starter-inoculated loins in comparison to the control loins (Table 2; evaluated sensory attributed marked with superscript T). Significantly stronger cheesy/rancid, buttery and almond-like odors were observed in starter-injected loins at storage temperatures of $5{ }^{\circ} \mathrm{C}$ in comparison to the control at the start of storage (week 3 )
(Table 2). These observations are in line with the results from the microbial study and the $\mathrm{pH}$ measurements. At the end of storage, the grassy odor of the starter-inoculated loins stored at $15^{\circ} \mathrm{C}$ significantly increased to a score of 3.5. The buttery odor decreased at lower temperatures, but significantly increased to 3.6 for starter-injected loins stored at $25^{\circ} \mathrm{C}$. The most important sensory attribute for the cured meat products studied was the cheesy/rancid odor, which significantly increased with rising storage temperature up to score 4.0 (Table 2). A multiple regression $(\alpha=0.1)$ was performed to explain the effect of volatile compounds on the overall odor and taste, and multiple regression models were calculated with all measured key volatile compounds (Table 3 ). The regression models show the significant volatile compounds that affected the overall odor and taste (Eqs. 1 and 2). The fact that a numerical relationship between volatile compounds and sensory attributes does not automatically imply that the volatile compounds isolated from food have a sensory impact on the food has to be taken into account (Supplemental material 4). The threshold values as well as the interactions with the food matrix and the mixture of volatile compounds led to typical sensory impressions [7, 36, 37]. The calculated model for the overall odor $(p=0.1)$ with coefficient of determination $\left(R^{2}\right)$ of $95.87 \%$ was:

Overall odor $=3.26-0.045 \times$ acetophenone -0.009

$\times$ benzaldehyde $+0.004 \times 2$-butanone +0.014

$\times$ 3-bethylbutanal $-0.001 \times 1$-Octen-3-ol.

The model for the overall taste $(p=0.1)$ with $R^{2}$ of $81.08 \%$ was calculated as:
Table 2 Results of the sensory evaluation (mean \pm standard deviation) for the cured loin batches cured with S. carnosus LTH 3838 (starter) against the control batch as a reference sample (scored to 3) at the start (week 3) and the end of storage (week 15) for overall odor and overall taste conducted with a sensory panel $(n=40)$, and grassy, buttery, almond-like, flowery/sweet and cheesy/rancid odor were evaluated with an olfactory-trained panel $(n=29)$

\begin{tabular}{|c|c|c|c|c|c|c|c|c|}
\hline \multirow[t]{2}{*}{ Sensory attribute } & \multicolumn{3}{|c|}{ Start of storage (week 3) } & \multicolumn{3}{|c|}{ End of storage (week 15) } & \multicolumn{2}{|c|}{ Effects ( $p$ value) } \\
\hline & Starter $5{ }^{\circ} \mathrm{C}$ & Starter $15^{\circ} \mathrm{C}$ & Starter $25^{\circ} \mathrm{C}$ & Starter $5^{\circ} \mathrm{C}$ & Starter $15^{\circ} \mathrm{C}$ & Starter $25^{\circ} \mathrm{C}$ & Time & Temp \\
\hline Overall odor & $2.8 \pm 1.1^{\mathrm{a}}$ & $3.2 \pm 1.0^{\mathrm{a}}$ & $2.9 \pm 1.1^{\mathrm{a}}$ & $2.9 \pm 1.1^{\mathrm{a}}$ & $3.3 \pm 1.1^{\mathrm{ab}}$ & $3.4 \pm 1.1^{\mathrm{b} *}$ & 0.079 & 0.054 \\
\hline Overall taste & $3.1 \pm 1.1^{\mathrm{a}}$ & $2.5 \pm 1.1^{\mathrm{b} *}$ & $2.9 \pm 1.1^{\mathrm{ab}}$ & $3.0 \pm 1.0^{\mathrm{a}}$ & $3.4 \pm 1.2^{\mathrm{a} \#}$ & $3.3 \pm 1.2^{\mathrm{a}}$ & 0.006 & 0.436 \\
\hline Grassy odor ${ }^{\mathrm{T}}$ & $2.7 \pm 1.2^{\mathrm{a}}$ & $2.8 \pm 1.1^{\mathrm{a}}$ & $2.9 \pm 1.2^{\mathrm{a}}$ & $3.3 \pm 1.2^{\mathrm{ab}}$ & $3.5 \pm 1.3^{\mathrm{a} * \#}$ & $2.8 \pm 1.2^{\mathrm{b}}$ & 0.032 & 0.491 \\
\hline Buttery odor ${ }^{T}$ & $3.6 \pm 1.2^{\mathrm{a} *}$ & $3.4 \pm 1.1^{\mathrm{a}}$ & $3.3 \pm 1.4^{\mathrm{a}}$ & $3.2 \pm 1.0^{\mathrm{a}}$ & $3.3 \pm 1.0^{\mathrm{a}}$ & $3.6 \pm 1.0^{\mathrm{a} *}$ & 0.771 & 0.912 \\
\hline Almond-like odor ${ }^{T}$ & $3.4 \pm 1.0^{\mathrm{a} *}$ & $3.5 \pm 0.9^{\mathrm{a} *}$ & $3.1 \pm 0.8^{\mathrm{a}}$ & $3.1 \pm 0.6^{\mathrm{a}}$ & $2.9 \pm 0.8^{\text {a\# }}$ & $2.7 \pm 1.0^{\mathrm{a}}$ & $<0.001$ & 0.071 \\
\hline Flowery/sweet odor ${ }^{\mathrm{T}}$ & $3.6 \pm 1.5^{\mathrm{a}}$ & $3.4 \pm 1.2^{\mathrm{a}}$ & $3.1 \pm 1.3^{\mathrm{a}}$ & $3.2 \pm 1.2^{\mathrm{a}}$ & $3.0 \pm 1.2^{\mathrm{a}}$ & $3.2 \pm 1.5^{\mathrm{a}}$ & 0.351 & 0.603 \\
\hline Cheesy/rancid odor ${ }^{\mathrm{T}}$ & $3.6 \pm 1.3^{\mathrm{a} *}$ & $3.0 \pm 1.2^{\mathrm{ab}}$ & $2.9 \pm 1.4^{\mathrm{b}}$ & $3.4 \pm 1.3^{\mathrm{a}}$ & $3.9 \pm 1.0^{\mathrm{a} \# *}$ & $4.0 \pm 1.6^{\mathrm{a} \# *}$ & 0.003 & 0.978 \\
\hline
\end{tabular}

Different letters indicate significant differences between batches within the same week, ${ }^{\#}$ indicates significant differences over time within one sensory attribute and $*$ indicates significant differences between reference score of 3 (confidence level $\alpha=0.05$ ). The statistical effects of time and temperature (temp.) are given as $p$ value (multiple ANOVA, confidence level $\alpha=0.05$ )

${ }^{\mathrm{T}}$ Sensory analysis was conducted with an olfactory-trained panel 


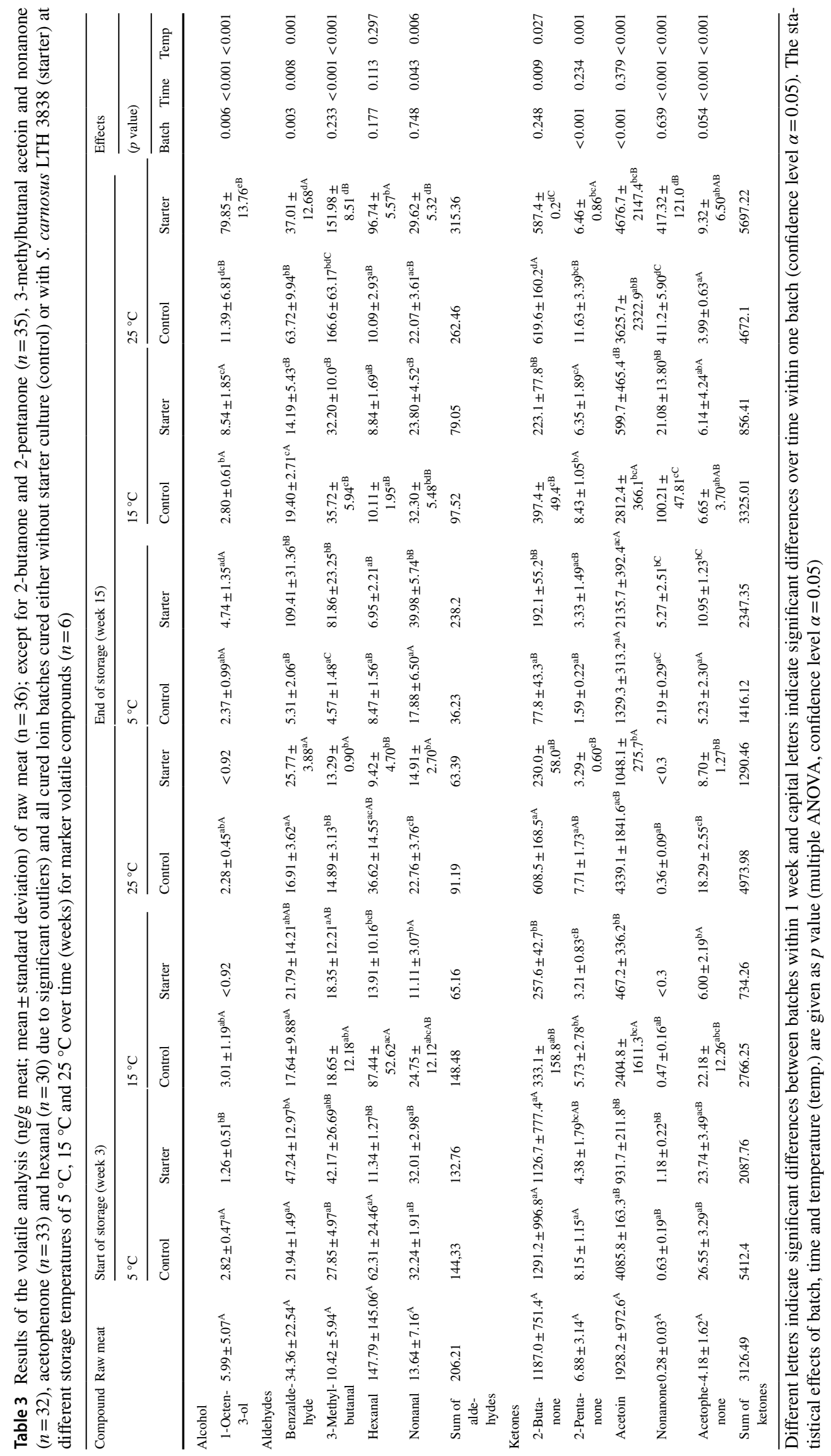


Overall taste $=2.14-0.007 \times 3$-methylbutanal +0.026

$\times$ nonanal $+0.010 \times 1$-octen-3-ol $+0.103 \times 2$-pentanone.

The multiple regression showed that a mixture of volatile compounds produced the typical cured-ham odor and taste as described by other authors using gas chromatography-olfactometry $[7,38]$. They conclude that the most important volatile compounds in terms of basic contribution to cured-ham odor and taste are 3-methylbutanal, hexanol, limonene, 3-methylbutanol, hexanal, 2-nonanone and benzaldehyde for Spanish dry-cured hams [38]. In addition, these cured-ham relevant volatiles were found as well in cured loins [4-6]. In the present study, four of these compounds were investigated, and 3-methylbutanal, nonanone and benzaldehyde can be found in the models described above (Eqs. 1 and 2). Nevertheless, the term 'cured-ham flavor' and the impression of odor and taste between a Spanish drycured ham and a cured pork loin can and will differ, but the identified key volatile compounds can be detected in both products and may be selected as typical for cured and/or salted meat products. Moreover, models for sensory attributes and volatile compounds of Iberian hams were calculated [7]. In this study, 3-methylbutanal was contributed to acorn odor, acorn flavor, rancid taste, rancid odor and fatty pungent flavor and benzaldehyde was present in the equation for acorn odor and nonanone in acorn flavor [7]. The substance 3-methylbutanal was present in all sensory attributes and had a great impact not only on Iberian ham, but also on North European cured loins.

\section{Volatile analysis}

During processing and storage, ketones were the dominant volatile group, followed by aldehydes. The major chemical classes, namely alcohols, aldehydes and ketones, of the volatile compounds studied were in agreement with a wide range of literature for dry-cured ham products of different origins $[8,12,14,15]$. Nevertheless, for cured pork loins, different amounts of alcohols, acids, ketones and aldehydes as major groups were described, but all studies come to the conclusion that compounds from Maillard reaction and Strecker degradation of amino acids were more characteristic for cured pork loins than lipid oxidation products [4-6]. Moreover, it was pointed out that the activity of microorganisms and the addition of spices seem to highly affect the volatile profile of cured pork loins [4-6]. In general, alcohols have limited influence on the flavor profile of cured meat products due to their high threshold values [8, 14]. Compounds such as 1-octen-3-ol and 1-penten-3-ol, with mushroom-like and onion-like odors, can contribute to the flavor of cured ham and loin $[4,8]$. In the current study, temperature, time and the inoculation of the starter culture affected the amount of 1-octen-3-ol (Table 3). At the start of storage (week 3), the content of 1-octen3-ol was higher for the control samples than for the starter batch. During storage, the content of this compound increased for the starter batch up to $4.74 \mathrm{ng} / \mathrm{g}$ meat, $8.54 \mathrm{ng} / \mathrm{g}$ meat and $79.85 \mathrm{ng} / \mathrm{g}$ meat for storage temperatures of $5{ }^{\circ} \mathrm{C}, 15^{\circ} \mathrm{C}$ and $25^{\circ} \mathrm{C}$, respectively (Table 3 ). The addition of $S$. carnosus, as well as higher temperatures, increased the 1-octen-3-ol content in the cured loins. The linear alcohol 1-octen-3-ol, which was also found in Spanish cured loins, is produced by beta scission pathway or lipoxygenases and both processes are influenced by temperature and/or intrinsic and microbial lipolytic activity [4, 5, 39, 40]. In addition, 1-octen-3-ol was only found in inoculated meat samples and seemed to derive from microbial metabolism [41].

Aldehydes. Low odor thresholds characterize the group of aldehydes, and many of these compounds were identified as key volatile compounds in cured-ham and cured loin [4-6, 8, 14]. The branched-chain aldehyde 3-methylbutanal, the aromatic benzaldehyde and the linear aldehydes hexanal and nonanal were detected in concentrations of $10.4 \mathrm{ng} / \mathrm{g}$ meat, $34.4 \mathrm{ng} / \mathrm{g}$ meat $147 \mathrm{ng} / \mathrm{g}$ meat and $13.6 \mathrm{ng} / \mathrm{g}$ meat, respectively (Table 3 ). The parameters of temperature, time and starter culture influenced the amount of these compounds, except for hexanal. For all temperatures, 3-methylbutanal and benzaldehyde reached their highest content at the end of storage (except for control at $5{ }^{\circ} \mathrm{C}$ ), as different authors observed during longer ripening times in cured hams and loins $[5,7,42]$. In addition, benzene acetaldehyde, 3-methylbutanal and benzaldehyde were also studied as key products of amino acid catabolism of microorganisms or Strecker degradation in Spanish cured loins [4, 6]. At a storage temperature of $5{ }^{\circ} \mathrm{C}$, benzaldehyde and 3-mehylbutanal significantly decreased in the control batches, whereas these two compounds significantly increased in the starterinjected loins (Table 3 ). With rising storage temperatures $\left(15^{\circ} \mathrm{C}\right.$ and $\left.25^{\circ} \mathrm{C}\right)$, the significant effect of the starter culture was not observed. The branched (3-methylbutanal) and aromatic aldehydes (benzaldehyde) are degradation products of the amino acids valine, isoleucine, leucine and phenylalanine [43] and were increased by the inoculation of coagulase-negative staphylococci in raw fermented sausages [33, 44, 45]. For Staphylococcus xylosus, 3-methylbutanal was produced from $\alpha$-ketoisocaproic acid [11]. At higher temperatures, the activity of intrinsic muscle enzymes, as well as microbial enzymes of autochthonous microbiota or inoculated bacteria, rose, so more precursors for volatile compounds were available. These findings are supported by significant correlations between tyrosine and 3-methylbutanal content in all starter-inoculated loins $\left(5^{\circ} \mathrm{C}, 15^{\circ} \mathrm{C}\right.$ and $\left.25^{\circ} \mathrm{C} ; p<0.05\right)$ and in control loins at $15^{\circ} \mathrm{C}$ and $25^{\circ} \mathrm{C}$ $(p<0.05)$. In addition, a significant correlation between tyrosine and benzaldehyde for starter-injected loins stored at $5{ }^{\circ} \mathrm{C}$ and $15^{\circ} \mathrm{C}(p<0.05)$ and control loins $\left(5^{\circ} \mathrm{C}\right.$ and $25^{\circ} \mathrm{C}$; 
$p<0.05)$ supported this trend. These findings are in line with the increased activity of staphylococcal aminopeptidase that released L-methionine, L-leucine and L-phenylalanine residues that can further be degraded to their respective amino acids and converted to their branched-chain aldehydes (e.g., 3-methylbutanal) and acids (e.g., 3-methylbutanoic acid) that are involved in flavor perception [11, 32, 43]. Moreover, the proteolytic activity of the $S$. carnosus LTH 3838 strain at storage temperature of $5{ }^{\circ} \mathrm{C}$ was higher than that of the autochthonous microbiota and/or intrinsic enzymes of the control loins. Thus, the starter culture contributed to a higher volatile content, which can be underlined with the high sensory rating for cheesy/rancid odor (Table 2). The contribution of staphylococci to the odor and taste of cured meat products has been the focus of many studies, and it is known that these microorganisms are involved in the production of branched-chain aldehydes through $\alpha$-ketoisocaproic acid $[11,12]$. The straight chain aldehydes hexanal and nonanal originate from chemical fatty acid degradation [42] and only low amounts of nonanal were detected in the raw material (Table 3). The multiple ANOVA $(\alpha=0.05)$ showed significant effects for time and temperature for nonanal. The starter-injected loins contained lower amounts of hexanal and nonanal than the control at the start of storage, except for the treatment at $5{ }^{\circ} \mathrm{C}$ for nonanal and $25^{\circ} \mathrm{C}$ for hexanal. The nonanal content for all starter-inoculated loins significantly increased during storage, whereas the control batches stayed constant (exception: control of $5{ }^{\circ} \mathrm{C}$ decreased). Increasing temperature and nitrate addition increased the content of butanal, pentanal, hexanal and decanal in fermented sausages [45]. However, other researchers observed no influence of the ripening time on the several saturated (pentanal, hexanal, nonanal) and unsaturated aldehydes (2-octenal, 2,4-decadienal) in Spanish cured loins [5].

Ketones The major volatile compounds within the ketones were acetoin and 2-butanone and this result is in line with studies of Spanish cured loins [4-6]. In general, methyl ketones are produced by fatty acid $\beta$-oxidation [46] and some authors demonstrated that staphylococci can influence the methyl ketone level [33, 47]. In addition, the ketone acetoin is produced by carbohydrate catabolism [33, 46]. In the raw meat, these compounds were highly concentrated, with $1928 \mathrm{ng} / \mathrm{g}$ meat and $1187 \mathrm{ng} / \mathrm{g}$ meat, respectively. At the start of storage, lower concentrations of acetoin and 2-butanone were observed for the starter-inoculated loins than for the control (Table 3). The contents of acetoin and 2-butanone increased with rising temperature. The levels of 2-butanone for starter-injected loins were found lower at $15{ }^{\circ} \mathrm{C}$ and $25{ }^{\circ} \mathrm{C}$ than the control at the end of storage (Table 3). Moreover, the storage at $5{ }^{\circ} \mathrm{C}$ significantly decreased the content of 2-butanone from $1291 \mathrm{ng} / \mathrm{g}$ and $1126 \mathrm{ng} / \mathrm{g}$ meat to $77 \mathrm{ng} / \mathrm{g}$ meat and $192 \mathrm{ng} / \mathrm{g}$ meat for control and starter-inoculated loins, respectively. Another methyl ketone investigated was 2-pentanone, which is associated with a sweet/fruity odor [33] and was detected with low peak areas in studies of Spanish cured loins $[4,5]$. It was found in the raw material with $6.9 \mathrm{ng} / \mathrm{g}$ meat (Table 3 ). A storage at $5{ }^{\circ} \mathrm{C}$ significantly decreased the 2-pentanone concentration for the control loins. With higher storage temperatures $\left(15^{\circ} \mathrm{C}\right.$ and $\left.25^{\circ} \mathrm{C}\right)$, the 2-pentanone content significantly increased for the control and starter-inoculated loins, but the starter batches showed lower concentrations of 2-pentanone, so batch and temperature influenced the 2-pentanone content in cured loins. Nonanone was found in low amounts $(0.36 \mathrm{ng} / \mathrm{g}$ to $1.18 \mathrm{ng} / \mathrm{g}$ meat) or was under the detection limit in some cured loins at the start of storage (Table 3). The storage process significantly increased the nonanone content for all batches. A storage temperature of $5{ }^{\circ} \mathrm{C}$ resulted in significantly higher amounts of nonanone in the starter-inoculated loins but, at $15{ }^{\circ} \mathrm{C}$, the nonanone content of the control was significantly higher than that of the starter batch. At $25{ }^{\circ} \mathrm{C}$, the nonanone content showed no significant differences between the control and starterinjected loins. The nonanone content in Spanish cured loins stayed constant over a ripening time of 55 days [5]. Acetophenone is a ketone generated by phenylalanine degradation of staphylococci [28]. During processing, the acetophenone content increased for all batches in comparison to the raw material (Table 3). At the beginning of storage, the loins inoculated with S. carnosus contained lower amounts of acetophenone than the control loins. During storage, the acetophenone content significantly decreased for all control loins to a range of 4-6.6 ng/g meat (Table 3), whereas at a storage temperature of $5{ }^{\circ} \mathrm{C}$ a significant decrease of acetophenone content for the starter-inoculated loins to $10.95 \mathrm{ng} / \mathrm{g}$ meat was observed and starter-injected loins at higher storage temperature $\left(15^{\circ} \mathrm{C}\right.$ and $\left.25^{\circ} \mathrm{C}\right)$ stayed at the initial level. Acetophenone is generated by phenylalanine as well as benzaldehyde; maybe there is a precursor competition for phenylalanine between those volatiles and/or a preferred phenylalanine reaction of staphylococci. To prove this assumption, more studies need to be carried out. Time and temperature had a significant effect on the acetophenone content in cured loins. The volatile acetophenone was detected in fermented sausages inoculated with Staphylococcus carnosus and S. xylosus $[44,48]$, but it is the first time that acetophenone was detected in cured pork loin inoculated with $S$. carnosus. The storage process at $5{ }^{\circ} \mathrm{C}$ and the addition of the $S$. carnosus strain increased the alcohol by a factor about 2 , the sum of aldehydes by about 6.5 and the sum of ketones by about 1.7 in comparison to the cured loins without a starter culture.

In conclusion, the North European cured loins showed different key volatile characteristics at the storage temperatures investigated. The content of the aldehydes 3-methylbutanal and benzaldehyde, as well as the alcohol 1-octen-3-ol, increased with rising temperatures. The results give a first 
impression of the complexity of the interaction of processing factors, microbiota and flavor generation.

Acknowledgements This IGF Project of the FEI is/was supported via $\mathrm{AiF}$ within the program for promoting the Industrial Collective Research (IGF) of the German Ministry of Economics and Energy (BMWi), based on a resolution of the German Parliament. Project number AiF 17687 N. We thank our student assistant Karen Jo Oeßelmann for her assistance during cured loin analysis. This study was carried out at the University of Hohenheim, Department of Food Physics and Meat Science, Stuttgart, Germany.

Funding Open Access funding enabled and organized by Projekt DEAL.

\section{Compliance with ethical standards}

Conflict of interest The authors declare that they have no known competing financial interests or personal relationships that could have appeared to influence the work reported in this article.

Compliance with ethics requirements This article does not contain any studies with human or living animal subjects.

Open Access This article is licensed under a Creative Commons Attribution 4.0 International License, which permits use, sharing, adaptation, distribution and reproduction in any medium or format, as long as you give appropriate credit to the original author(s) and the source, provide a link to the Creative Commons licence, and indicate if changes were made. The images or other third party material in this article are included in the article's Creative Commons licence, unless indicated otherwise in a credit line to the material. If material is not included in the article's Creative Commons licence and your intended use is not permitted by statutory regulation or exceeds the permitted use, you will need to obtain permission directly from the copyright holder. To view a copy of this licence, visit http://creativecommons.org/licenses/by/4.0/.

\section{References}

1. Toldrá F (2002) Dry-cured meat products. Food \& Nutrition Press, Inc. https://doi.org/10.1002/9780470385111.ch3

2. Bosse R, Müller A, Gibis M, Weiss A, Schmidt H, Weiss J (2018) Recent advances in cured raw ham manufacture. Crit Rev Food Sci Nutr 58(4):610-630. https://doi.org/10.1080/10408 398.2016.1208634

3. Pegg RB (2004) CURING I production procedures. In: Jensen WK (ed) Encyclopedia of meat sciences, 1st edn. Elsevier, Oxford, pp 349-360. https://doi.org/10.1016/B0-12-464970-X/00150-1

4. Muriel E, Antequera T, Petrón MJ, Andrés AI, Ruiz J (2004) Volatile compounds in Iberian dry-cured loin. Meat Sci 68(3):391400. https://doi.org/10.1016/j.meatsci.2004.04.006

5. Ventanas S, Ventanas J, Estévez M, Ruiz J (2010) Analysis of volatile molecules in Iberian dry-cured loins as affected by genetic, feeding systems and ingredients. Eur Food Res Technol 231(2):225-235. https://doi.org/10.1007/s00217-010-1274-y

6. Soto E, Hoz L, Ordóñez JA, Hierro E, Herranz B, López-Bote C, Cambero MI (2010) Volatile profile and sensory characteristics of dry-cured loins as affected by feeding level in the period previous to the late fattening phase and by rearing system of Iberian pigs. J Muscle Foods 21(4):636-657. https://doi.org/10.111 $1 / \mathrm{j} .1745-4573.2010 .00210 . \mathrm{x}$
7. García-González DL, Tena N, Aparicio-Ruiz R, Morales MT (2008) Relationship between sensory attributes and volatile compounds qualifying dry-cured hams. Meat Sci 80(2):315-325. https ://doi.org/10.1016/j.meatsci.2007.12.015

8. Narváez-Rivas M, Gallardo E, León-Camacho M (2012) Analysis of volatile compounds from Iberian hams: a review. Grasas Aceites 63(4):432-452. https://doi.org/10.3989/gya.070112

9. Dirinck P, Van Opstaele F, Vandendriessche F (1997) Flavour differences between northern and southern European cured hams. Food Chem 59(4):511-521. https://doi.org/10.1016/S0308 -8146(97)00012-5

10. Gibis M, Fischer A (2004) Ethnic meat products I Germany. In: Jensen WK (ed) Encyclopedia of meat sciences. Elsevier, Oxford, pp 444-451. https://doi.org/10.1016/B0-12-464970-X/00272-5

11. Beck HC, Hansen AM, Lauritsen FR (2002) Metabolite production and kinetics of branched-chain aldehyde oxidation in Staphylococcus xylosus. Enzyme Microb Technol 31(1-2):94-101. https ://doi.org/10.1016/S0141-0229(02)00067-4

12. Larrouture C, Ardaillon V, Pépin M, Montel MC (2000) Ability of meat starter cultures to catabolize leucine and evaluation of the degradation products by using an HPLC method. Food Microbiol 17(5):563-570. https://doi.org/10.1006/fmic.2000.0353

13. Bosse R, Gibis M, Schmidt H, Weiss J (2016) Nitrate reductase activity of Staphylococcus carnosus affecting the color formation in cured raw ham. Food Res Int 85:113-120. https://doi. org/10.1016/j.foodres.2016.04.021

14. Sabio E, Vidal-Aragón MC, Bernalte MJ, Gata JL (1998) Volatile compounds present in six types of dry-cured ham from south European countries. Food Chem 61(4):493-503. https://doi. org/10.1016/S0308-8146(97)00079-4

15. Sánchez-Peña CM, Luna G, García-González DL, Aparicio R (2005) Characterization of French and Spanish dry-cured hams: influence of the volatiles from the muscles and the subcutaneous fat quantified by SPME-GC. Meat Sci 69(4):635-645. https://doi. org/10.1016/j.meatsci.2004.10.015

16. Sunesen LO, Dorigoni V, Zanardi E, Stahnke L (2001) Volatile compounds released during ripening in Italian dried sausage. Meat Sci 58(1):93-97. https://doi.org/10.1016/S0309-1740(00)00139-X

17. Martín A, Asensio MA, Bermúdez ME, Córdoba MG, Aranda E, Córdoba JJ (2002) Proteolytic activity of Penicillium chrysogenum and Debaryomyces hansenii during controlled ripening of pork loins. Meat Sci 62(1):129-137. https://doi.org/10.1016/S0309 -1740(01)00238-8

18. Martín A, Córdoba JJ, Benito MaJ, Aranda E, Asensio MA (2003) Effect of Penicillium chrysogenum and Debaryomyces hansenii on the volatile compounds during controlled ripening of pork loins. Int J Food Microbiol 84(3):327-338. https://doi.org/10.1016/ S0168-1605(02)00474-9

19. Stadnik J, Dolatowski ZJ (2013) Changes in selected parameters related to proteolysis during ageing of dry-cured pork loins inoculated with probiotics. Food Chem 139(1-4):67-71. https://doi. org/10.1016/j.foodchem.2013.01.079

20. Müller A, Fogarassy G, Bajac A, Weiss J, Weiss A, Schmidt H (2015) Selection of Staphylococcus carnosus strains based on in vitro analysis of technologically relevant physiological activities. Ann Microbiol. https://doi.org/10.1007/s13213-015-1133-y

21. Bosse née Danz R, Wirth M, Gibis M, Schmidt H, Weiss J (2017) Kinetics of volatile marker compounds during ripening of cured loins inoculated with Staphylococcus carnosus. J Sci Food Agric 97 (9):3050-3057. https://doi.org/10.1002/jsfa.8150

22. AOAC (1990) Official methods of analysis, 15th edn. Association of Official Analytical Chemists, Arlington

23. Bosse R, Wirth M, Konstanz A, Becker T, Weiss J, Gibis M (2017) Determination of volatile marker compounds in raw ham using headspace-trap gas chromatography. Food Chem 219:249 259. https://doi.org/10.1016/j.foodchem.2016.09.094 
24. Fischer UW (1997) Beeinflussung der Gehalte an Nitrit, freien Aminosaeuren und freien Fetten durch die Zugabe von Micrococcaceae in einem Kochschinkenmodel sowie deren Auswirkungen auf die sensorischen Eigenschaften. Thesis, Universität Hohenheim, Stuttgart

25. Bosse R, Gibis M, Schmidt H, Weiss J (2015) Kinetics of migration of colloidal particles in meat muscles in the absence and presence of a proteolytic enzyme to simulate non-motile bacteria penetration. Food Res Int 75:79-88. https://doi.org/10.1016/j. foodres.2015.05.054

26. Granato D, de Araújo Calado VM, Jarvis B (2014) Observations on the use of statistical methods in food science and technology. Food Res Int 55:137-149. https://doi.org/10.1016/j.foodr es.2013.10.024

27. Schlafmann K, Meusburger AP, Hammes WP, Braun C, Fischer A, Hertel C (2002) Starterkulturen zur Verbesserung der Qualität von Rohschinken. Fleischwirtschaft 82(11):108-114

28. Søndergaard AK, Stahnke LH (2002) Growth and aroma production by Staphylococcus xylosus, S. carnosus and S. equorum-a comparative study in model systems. Int J Food Microbiol 75(12):99-109. https://doi.org/10.1016/S0168-1605(01)00729-2

29. Sørensen BB, Jakobsen M (1996) The combined effects of environmental conditions related to meat fermentation on growth and lipase production by the starter culture Staphylococcus xylosus. Food Microbiol 13(3):265-274. https://doi.org/10.1006/ fmic. 1996.0032

30. Harkouss R, Astruc T, Lebert A, Gatellier P, Loison O, Safa H, Portanguen S, Parafita E, Mirade P-S (2015) Quantitative study of the relationships among proteolysis, lipid oxidation, structure and texture throughout the dry-cured ham process. Food Chem 166:522-530. https://doi.org/10.1016/j.foodchem.2014.06.013

31. Waade C, Stahnke LH (1997) Dried sausages fermented with Staphylococcus xylosus at different temperatures and with different ingredient levels. Part IV. Amino acid profile. Meat Sci 46(1):101-114. https://doi.org/10.1016/S0309-1740(96)00089-7

32. Casaburi A, Villani F, Toldrá F, Sanz Y (2006) Protease and esterase activity of staphylococci. Int J Food Microbiol 112(3):223229. https://doi.org/10.1016/j.ijfoodmicro.2006.04.008

33. Berdagué JL, Monteil P, Montel MC, Talon R (1993) Effects of starter cultures on the formation of flavour compounds in dry sausage. Meat Sci 35(3):275-287. https://doi.org/10.1016/03091740(93)90033-E

34. Leroy F, Verluyten J, De Vuyst L (2006) Functional meat starter cultures for improved sausage fermentation. Int J Food Microbiol 106(3):270-285. https://doi.org/10.1016/j.ijfoodmicr o.2005.06.027

35. Toldrá F, Flores M, Sanz Y (1997) Dry-cured ham flavour: enzymatic generation and process influence. Food Chem 59(4):523530. https://doi.org/10.1016/S0308-8146(97)00013-7
36. Buettner A, Beauchamp J (2010) Chemical input—sensory output: diverse modes of physiology-flavour interaction. Food Qual Prefer 21(8):915-924. https://doi.org/10.1016/j.foodqual.2010.01.008

37. Grosch W (1993) Detection of potent odorants in foods by aroma extract dilution analysis. Trends Food Sci Technol 4(3):68-73. https://doi.org/10.1016/0924-2244(93)90187-F

38. Carrapiso AI, Ventanas J, García C (2002) Characterization of the most odor-active compounds of Iberian Ham headspace. J Agric Food Chem 50(7):1996-2000. https://doi.org/10.1021/jf011094e

39. Jelen H (2011) Food flavors: chemical, sensory and technological properties. CRC Press, Boca Raton

40. Toldrá F (1998) Proteolysis and lipolysis in flavour development of dry-cured meat products. Meat Sci 49(Supplement 1):S101S110. https://doi.org/10.1016/S0309-1740(98)90041-9

41. Wang Y, Li Y, Yang J, Ruan J, Sun C (2016) Microbial volatile organic compounds and their application in microorganism identification in foodstuff. TrAC Trends Anal Chem 78:1-16. https:// doi.org/10.1016/j.trac.2015.08.010

42. Pérez-Palacios T, Ruiz J, Martín D, Grau R, Antequera T (2010) Influence of pre-cure freezing on the profile of volatile compounds during the processing of Iberian hams. J Sci Food Agric 90(5):882-890. https://doi.org/10.1002/jsfa.3899

43. Ardö Y (2006) Flavour formation by amino acid catabolism. Biotechnol Adv 24(2):238-242. https://doi.org/10.1016/j.biotechadv .2005 .11 .005

44. Olesen PT, Meyer AS, Stahnke LH (2004) Generation of flavour compounds in fermented sausages - the influence of curing ingredients, Staphylococcus starter culture and ripening time. Meat Sci 66(3):675-687. https://doi.org/10.1016/S0309-1740(03)00189-X

45. Stahnke LH (1995) Dried sausages fermented with Staphylococcus xylosus at different temperatures and with different ingredient levels-Part II. Volatile components. Meat Sci 41(2):193-209. https://doi.org/10.1016/0309-1740(94)00069-J

46. Fadda S, Lebert A, Leroy-Sétrin S, Talon R (2002) Decarboxylase activity involved in methyl ketone production by Staphylococcus carnosus 833, a strain used in sausage fermentation. FEMS Microbiol Lett 210(2):209-214. https://doi.org/10.1016/S0378 -1097(02)00631-6

47. Montel MC, Reitz J, Talon R, Berdagué JL, Rousset-Akrim S (1996) Biochemical activities of Micrococcaceae and their effects on the aromatic profiles and odours of a dry sausage model. Food Microbiol 13(6):489-499. https://doi.org/10.1006/fmic.1996.0056

48. Stahnke LH (1999) Volatiles produced by Staphylococcus xylosus and Staphylococcus carnosus during growth in sausage minces part II. The influence of growth parameters. LWT Food Sci Technol 32(6):365-371. https://doi.org/10.1006/fstl.1999.0560

Publisher's Note Springer Nature remains neutral with regard to jurisdictional claims in published maps and institutional affiliations. 